MedieKultur | Journal of media and communication research | ISSN 1901-9726

Article

\title{
Risk communication as an operation meant to produce and share audiences
}

\section{Daniela Korbas-Magal}

MedieKultur 2010, 49, 68-80

Published by SMID | Society of Media researchers In Denmark | www.smid.dk The online version of this text can be found open access at www.mediekultur.dk

In this article, Luhmann's system theory is used as a theoretical framework for analysing the way risk communicators view their social functions. Narrated experiences from risk communicators in practice facilitate an understanding of risk communication as both an external irritation to society and part of the mass communication system. They also aid in clarifying how perceptions of audiences are reflected in the risk-communication strategies. The analysis is based on qualitative data collected from in-depth interviews conducted with 22 risk communicators (scientific professionals, spokespeople and journalists) in Israel. Thematic areas reflected in interviewees' reported strategies embody their perception of audiences. Those themes include: the reduction of complexities; coding and sorting of information; autopoiesis (realisation/ non-realisation of the risk); rationality; inherent paradoxes; and schema formation. In sum, the findings suggest that risk communicators play a major role in defining, creating and producing audiences for the mass communication system.

Communication about potential risks is presently viewed in the professional milieu as a critical life-saving operation for society. Risk communication is society's way of informing its audiences of crises, conflicts, malfunctions, hazards and potential disasters that may come about and shake its stability and potency (CDC, 2002).

Luhmann's system theory can thus be an unerringly appropriate theoretical framework for analysis and discussion of risk communication. It possesses a great deal of explanatory 
power since it views society as a system comprised of a selective collection of requisites related to each other (Bergmans, 2008). A close reading of Luhmann's work facilitates an understanding of risk as an external nuisance to social systems, yet leaves me wondering what the nature of risk communication should be. Even though crises and conflict (via the general information/ non- information code) are criteria which Luhmann himself lists as the guiding principles for the selections made by the mass communication system (Luhmann, 2000), a full notion of risk communication remains explicitly unanswered. This article draws on data collected from in-depth interviews conducted with 22 senior risk-communication professionals: senior risk managers, spokespeople of the Israeli Ministry of Environmental Protection and Ministry of Health, and health and environmental journalists in Israel. These people are in charge of communicating about risk to the Israeli audience.

Jacob A. is a senior governmental scientist and risk manager. He is in charge of communicating risk information and knowledge about hazardous substances to audiences in Israel.

The more risk communication concerns straightforward scientific issues - the less I expect people to understand. That's why I filter many facts. I make things as simple as possible: Should people do something or refrain from action? Should they stay indoors or should they go outdoors? Interview with Jacob A

\section{Use of Luhmann's system theory in risk communication research}

Recently, there have been voices calling for a more innovative, inter-disciplinary approach to the study of risk communication in overlapping fields such as crisis communication (cf: Heath, 2009). Thus far, there have been numerous attempts to use new theories from various disciplines for applied studies and field research of risk communication. One example is Horsley's recent revision of the CAPI model (crisis adaptive audience information), which draws on constructionist theories of media (Horsley, 2009), or Sellnow's use of chaos theory for audience's informational needs in risk communication (Sellnow, 2009; Sellnow, Seeger \& Ulmer, 2003). A qualitative use of Luhmann's empirical foundations (i.e., the view of society as a compilation of related systems) as central for data analysis and interpretation hence suggests a fresh viewpoint in the study of risk communication and provides recent research agenda with a perspective on the possible application of Luhmann's empirical system theory for actual communicative settings. In other words, this study is an exemplification of how systems in general and specifically the mass communication system actually work. 


\section{On risks and risk communication according to Luhmann}

Luhmann's theory of risks and their meanings for modern societies is quite unique and stands out from other significant modern risk theories (e.g., Beck, Douglas and Giddens). While all agree on the reality of an uncertain future lacking an overall social navigating mechanism (Bergmans, 2008; Klinke et al., 2006; Renn, 2006, 2003), Luhmann provides a unique explanation of the reasons that have brought society to face this reality. In addition, Luhmann stresses the fact that even uncertainty itself is of a temporal nature. The risk lies in the future, yet even the future can only be observed in the present. Decisions are constantly made and thus the future can be altered at any given second. Let me try and make this point a bit clearer in the following.

Luhmann does not think technological developments have brought society to a position where it is subject to constant risks and lacks a central steering apparatus (Beck, 1992, $1995,1999,2009)$, nor does he think cultural or societal norms or factors have taken our society over thus far (Douglas, 1992; Giddens, 1990; Hansson, 2005, 2000; Renn, 1998). Rather, he attributes this reality to an increased dependence of society on decision-making, to a dominance of a linear notion of time, and to a sharpening contrast between decisionmakers (risk communicators) and those affected (audiences) (Bergmans, 2008, p. 176). First of all, Luhmann's (1993) reflections on risk are in many ways an extension of his perspective on ecology, in so far as ecological communications are but one form of risk communication in modern societies (Luhmann, 1989). He distinguishes risk from danger. Dangers and catastrophes have historically been part of our being, he asserts. What is new are catastrophes produced by our own decisions. Danger is harm that is externally produced or environmentally determined, whereas risk involves harm caused by our own decisions, and is therefore a normal and unavoidable creation of society (Luhmann, 1993). People in modern risk contexts are more and more conscious, and recognise that there are many different possible responses to risks and crises, and the chosen response is only one of many alternatives (Luhmann, 1993). Second, time in modern society is viewed in terms of before and after, and so the vagueness of the future becomes more visible. Third, it takes someone who is involved and part of everyday risk-management processes to take risk-related decisions. Hence, the gap between decision-makers and those affected becomes wider. This fills the audiences with feelings of lack of control, threat and anxiety.

Risk is an external nuisance to the social systems. Yet it differs from any other peripheral irritation since communication about it is a constitutive element of society (Luhmann, 1993). Risk - more than just being produced by our own decisions (Luhmann, 1993) - has to be managed and contained by individuals within the social context. This fact provides the central paradox outlined in this study: the blurred status of risk communication. Since risk itself is an external menace and communication in itself is the essential element of society - is risk communication a part of the social system? Is it an outer irritation to it? Is it an operation or is it an observation? And what do all these questions mean when it comes to 
risk communication's endpoint - the audiences? To try and answer these questions, I will first define the basic use of operation and observation in Luhmann's theory.

According to Luhmann (2000, p. 95), in order to examine the function of the mass communication as a social system in any way, one must bear in mind the basic distinction between an operation and an observation. Operation is the true-life happening of events. An observation, a particular form of operation, uses distinctions in order to describe a certain something (and only that certain something). Society is composed of communication, because communications are its fundamental elements and communicating is its primary operation. It can observe and control itself only through further communications (Luhmann, 1998). It becomes clearer now that risk communication is an operation. It also stems from here that threats to society can only appear in the form of communications about the environment produced by the social system itself.

The social systems observe themselves. The social system of mass communication hence finds itself in the most complicated state of all, since in addition to observing itself it is also responsible for observing society as a whole. A fundamental limitation lies in the fact that systems from within the society can only observe themselves, yet they cannot observe their blindness. The system's view, in other words, is very sequential and partial. Each system observes risks from its own temporal biases and limitations. If so, then risk communication (the mere fact of communicating about risks) is nothing but society posing a threat for its own continuation.

However, the interpretations offered by the Israeli risk communicators do not second that view. My interviewees suggest risk communication is actually an aid for society to keep the paradoxical cycle of observing and processing its self-created reality. This is done because of an enormous power-risk, communicators maintain. They are the only ones who decide who the audiences will be and what information they shall receive. In other words, if risks are what might shake the system as a whole, it is the risk communicators who decide if they will.

\section{The role of self-observation in managing complexities}

1. The various social systems, asserts Luhmann, support and encumber one another equally. What keeps society up and running is the fact that the systems cannot be replaced. Each system has its unique role and function, and only the sum of activities could maintain society as a whole. Problems and difficulties that stem from risks are hence continually displaced from one system to another (Luhmann, 1989). The system of mass communication becomes functionally differentiated from the others by adopting a specific form of observation in order to produce a coherent social reality (Luhmann, 2000). Luhmann is interested in how mass communication constructs its own reality, and how it comes to be operative for the social system (ibid). If I am to ask the same question for the case of risk communication, I would suggest that Luhmann would have been interested in know- 
ing how risk communicators construct the reality for their audiences (and whether this mission is at all achievable) and describing how an effective selection of information takes place in order to ensure a successful functioning of the system.

2. The audience's role in risk communication is hence twofold: on the one hand, the audience is the target of risk communication processes - the audience is for whom the social reality is produced. On the other hand, the audience is yet another observer from within the system. The role the system of mass communication plays with regards to the audience remains an unanswered matter in Luhmann's writings (Aguado, 2009).

3. There is seldom only one audience, but a differentiated range of audiences. Risk communication has to address different audiences with conflicting utterances. Risk communicators can communicate with themselves (i.e., they maintain an inner self-referential nature), but they cannot communicate with differentiated audiences.

4. As observers and as the essence that makes up the systems, the audiences, in terms of relative strength, are the weakest ones. Knowledge is exclusively owned by risk communicators, who are the ones responsible for producing the codes used to maintain the systems' operations (Luhmann, 2000). These codes, in order to maintain a sufficient level of coherence for the whole system, must be as generalised and abstract as can be. This empowers risk communicators and weakens the audiences. The decision of what is good for the public is rendered solely by the hands of risk communicators.

5. The meaning of audiences in such a context is the following: Assuming that (a) modern society is differentiated to such an extent that mass communication is nothing but another system, and that (b) risk is an irritation from the environment, and that (c) risk needs to be observed but can only be observed by those who specialise in its observation, how is communication about risks to be shared with various audiences across various systems of society? In other words, if audiences are fundamental to society (without them, what is society to subsist for?), and if they are constantly reproduced by the system of mass communication, then the question remains how does the mass communication system cope with risk communication in a society so differentiated? And if risks are continually shifted from one system to another, are audiences too? Who decides who the audiences are at any given time? And is risk communication a distinct feature of the mass communication system, or is it transferred from one system to another, like the risks themselves? Aguado (2009) suggests applying a meta-code of relevance/opacity to the system of mass communication, which unlike the case of information/non- information does not necessarily point to a selection of the unexpected or uncertain, but to a key distinction between what the communicators consider as relevant and what they do not. This distinction explains how the audience is systematically excluded from the system's 
operations and how the basic weakness I outlined earlier aids in producing mass communication audiences over and over again.

6. Another form manifesting risk communication's paradoxical nature lies in the very concept of self-observation. Self-observation presupposes a capability for meta-observation (to observe the observation) that demands a specific distinction between observer and actor (Luhmann, 2000). Nevertheless, within the social system of mass communication, the scope between the concepts of observing and acting is reasonably blurred. Risk communicators, as observers produce the reality they observe (latent in the processes of risk assessment and management) and observe the reality they produce (latent in the process that follows - risk communication). This is why there can be no self-reference here. I hence must assume, then, that hetero-reference (Luhmann, 2000) is the system's way of externalising its self-reference. By doing so (e.g., referring to the hetero's, the systems outside the system), the system imports its operational function. Risk communicators hence produce the audience since they are the very ones who decide who the audience is. At the same time, risk communicators' role is to serve as the audience's main observer. Risk communicators keep coming in and out of the mass communication system.

\section{Methodological background}

This article presents some of the initial findings of an ongoing research study recently carried out by the author, which draws on scenario-analysis and examines risk-communication information transmission sequences. The main sites of the study are the Israeli Ministry of Health and Ministry of Environmental Protection, to which the professional scientists and the spokespeople belong. The professional scientists were the first ones to be interviewed, and were chosen by their proximity to diverse health and environmental scenarios dealt with in the ongoing research project. The spokespeople of the Ministry of Health and Ministry of Environmental Protection were chosen for the same reason, as well as serving as key-informants, who recommended some relevant journalists to be included in the study. Other journalists were chosen due to their fluent coverage of health, environmental and scientific issues in the Israeli press. The reporters and editors who took part in the study are all active journalists, who (apart from one reporter who works for a minor website) work for large daily Israeli newspapers, which have both an online interface and a printed daily version. Some of the informants were dubious and apprehensive to begin with, but were soon ready to cooperate, and as rapport was established, they became increasingly eager to share their views. The 22 interviews were all conducted between October 2009 and February 2010.

Israel represents a particularly good fit for health and environmental risk-communication research since it is a particularly conflict-driven and security-endangered country. For this reason, it entails a basic risk-awareness, yet since health- and environment-related risks 
are not directly terror and conflict-related, they receive relatively little attention in Israeli press journalism. The described merging of demand and availability creates a good opportunity for risk-communication research in this specific context.

\section{Data gathering}

Twenty-two in-depth informant interviews (Bouma \& Ling, 2004) with Israeli chief professional scientists, spokespeople, reporters and editors, who represent the full risk-communication chain (scientists - spokespeople - reporters - editors) and deal with risk communication in their routine occupation, were conducted. Interview questions were designed based on Thompson and Bloom's (2000) model, and served to obtain insight into the way risk communicators view their professional every-day performance, duties and obligations. The interviewees reflect a variety of skilled backgrounds, as well as different professional duties and responsibilities. During the interviews, comprehensive research notes were taken. In addition, interviews were audio-taped, transcribed and then translated from Hebrew to English. Interviews lasted from 38 minutes to four and a half hours, with an average length of one hour and twenty minutes. Data were analysed using a typical actions framework' (Bouma \& Ling, 2004).

\section{Findings: strategies that risk communicators use}

The risk communicators emphasised that communicating risk is a complicated and inherently tension-filled task. Themes emerged around the presentation of knowledge and information, the features of paradox and rationality, and the never ending cycle of restrictions through which risk-communication must manoeuvre.

\section{Sorting information: Fragmented presentations of knowledge}

Interviewees all stressed the inevitability of sorting information, i.e., the need to present the scientific and professional knowledge in a fragmented way designed to answer common questions that may rise, rather than to expand the recipients' knowledge or understanding of the subject matter. Luhmann (2000, p. 27) has done well in phrasing this necessity: "The principle of selection now seems to be that these requirements are intensified for the purpose of the mass communication and that more attention must be given to making the information readily understandable for the broadest possible circle of receivers."

"I have only one mission: the information has to be clear. And when I say clear, I mean it has to bring to mind as few questions and misunderstandings as possible" (Abraham, M., chief risk manager, Air Pollution Department, the Ministry of Environmental Protection). When asked how he relates to the mission of fully transmitting knowledge to the audience, Jonathan Y., reporter in one of Israel's daily newspapers, replied: "Fully... that's a philosophical matter. Yeah, it's important I guess, but there are other professional obligations I am 
eminently committed to", referring to the need to simplify and sort: present only certain fragments of the knowledge.

Akin to the classic work of Galtung and Ruge (1970), and to the latest publication provided by Preston (2009), Luhmann mentions a brief selection of information criteria Journalists tend to have. The pertinent principles of selection Luhmann (2000, p. 28) has pointed out were likewise evident in the research data:

a. Maintaining the element of surprise by marked discontinuity: the journalists emphasised the professional demand for news that is new. Hence, when dealing with continuous matters, such as the swine influenza, journalists stated they were always trying to create an interrupted sequence.

b. The preference of conflict over convergence: journalists favour disjunction, disagreements and squabbles. This tendency is opposed to the risk managers' and the spokespeople's affinity to present only their organisation's policies and views.

c. Quantities as an attention grabber: journalists asses the importance of an event by the numbers it contains. The fewer impingements, the less exciting.

d. Local relevance: if an event has an application to the local context, it is sure to receive more attention.

e. Norm violations: journalists are constantly searching for atrocities, abominations and breaches. Unlike them, risk managers and spokespeople are only concerned about concealing those.

f. Personal attribution of actions: journalists are always interested in knowing who or what stands behind an action. In contrast, risk managers and spokespeople are not always keen on attributing risk information to a certain individual.

g. The prerequisite of topicality: news items concentrate on individual cases - incidents, accidents, malfunctions, new ideas (Luhmann, 2000, p. 33), or as Armand H. (risk manager, the Ministry of Health) put it: "The information we release must come with a headline."

h. The prerequisite of recursivity: events must be assigned to a broader cycle of events, be it an assignation to a pre-known meaning or narrative.

\section{Binary coding}

Social systems can be viewed as coded forms of communication that arise out of the functionally differentiated nature of modern and complex societies (Luhmann, 2000). Risk communication thus covers its own inner forms of coding which are responsible both for closing it off operationally from its own environment and differentiating it internally from other social systems (Luhmann, 1989). The coding, according to Luhmann, is based on a binary distinction. Any operation of the system can eventually be condensed to a selection from a binary differentiation. $X$ can either be risky or not. Citizens can only be affected or not be affected. They should only fear or not fear etc. Jacob A., senior scientist and risk manager, did refer to the operation of risk communication under the modus operandi of the binary 
coding: "My goal is for the audience to discern: do's/ don't do's; hazardous/not hazardous; endangering/not endangering."

\section{Rationality as a means to reduce complexities for society}

"I always have to be very 'straight-to-the-point' and very resolved" (Shawn M., Ministry of Environmental Affairs, spokesperson). Rationality and prudence were contemplated as the best means to conquer ramifications. All risk communicators agreed that reduction of complexities is a crucial strategy that must be applied in order to sustain social order, and that the means of achieving this are by maintaining high levels of logic, coherence and argumentation. Luhmann (2000) has claimed that by choosing limited and lucid portions of information, the social system filters social convolutions.

\section{An autopoietic closure: the realisation/non-realisation of the risk}

By re-describing the social system in light of the concept of autopoiesis (self-creation), Luhmann has set one of the most important theoretical foundations for $21^{\text {st }}$ century sociology (Harris, 1995). In modern society, he asserts, there no longer exists a politically pre-defined elite which is responsible for managing audience life. As a substitute, what previously were small systemic parts (such as individual institutions) have now become meticulous social systems, which are actually decidedly explicit forms of suggestive communication (Luhmann, 2000, p. 15). Each system operates under its own self-creation, and thus requests its own fundamental conclusions. The realisation/non-realisation of the risky event is in itself a point of autopoiesis. Risk communicators may not be the ones who control the risk and its realisation, but they are the ones who take the decisions influenced by the realisation/ non-realisation of the risk.

"I am nothing but a tool, used by society to apprehend: did this happen or not? Why and how" (Maureen G., Reporter, environmental issues, for one of Israel's leading daily newspapers).

\section{Schema formation}

Risk goes far beyond the individual's world of experience (Luhmann, 2000, p. 110). Very few individuals have experienced an actual terror attack, a natural disaster, or a plague. He or she can, at best, activate experiences of their own that fit the event's perceived scheme (Luhmann, 2000, p. 111). Mass communication functions (i.e., the spokespeople and the journalists), too, are disparate regarding the task; and when the spokespeople and journalists turn to professional and scientific data, they will be presented with professional knowledge which cannot be understood without adequate prior knowledge. Hence, they will only be given one and the same amount of knowledge and ignorance at the same time. For this reason, states Luhmann, the media has developed the mechanism of schema formation (ibid). By this term, Luhamnn refers to a pre-planned representation pattern, which the media use to dispense risk communication materials. The individual, explains Luhmann 
(ibid, p. 112), needs schemata because they structure memory, but they do not determine action. Schema formation, according to Luhmann, is an inevitable part of society's character (society could not manage risk information if it was not handed to it in this manner), yet at the same time it prevents society from recognising deviations, constraints and opportunities for action (since it leaves no space for ingenious self-construal).

\section{Paradoxes as an inherent feature of risk communication}

The system of mass communication, contends Luhmann, is crammed with paradoxes, like a pomegranate is filled with seeds. One of the main paradoxes that is part of this fundamental nature is the ambiguous character of the distribution of information. "The mass communication disseminates ignorance in the form of facts which must continually be renewed so that no one notices" (Luhmann, 2000, p. 25). In this sense, Luhmann's theory resembles Beck's, who also claims the 'world risk society' is characterised with non-knowing, which can also be viewed as a form of collective denial (Beck, 2009, p. 123). The paradox of spreading lack of knowledge in the form of verifiable truths is reflected in the words of Claire K., science reporter for one of Israel's leading daily newspapers: "I'm quite sure the audience doesn't know (what lies beneath the scientific facts). Ideally, it shouldn't be like this, but there is a gap between idealism and reality."

\section{Risk communication operating in the system of mass communication under perpetual constrains and limitations}

"There's a need to eventually justify policies and decisions, and this could lead to certain ways to justification, especially when there's a dispute. I will have no choice but to present the picture that supports the national policy" (Armand H., risk manager, the Ministry of Health).

"There's a gap between ideals and reality. In real-life, we are operating under an incessant set of impediments: scarcity of time, pressure, the effect of commercial considerations that don't always go with the superlative of giving the information to the audience. We don't live in a university department of communications" (Jonathan Y., reporter for one of Israel's daily newspapers).

Apart from time pressure, which is a well-known and well-conferred factor in journalistic work (Preston, 2009, p. 66), the above quotations illustrate some additional significant constraints and limitations under which risk communication is compelled to operate. Journalistic values, attitudes and practices, for instance, are increasingly influenced and shaped by the reality that surrounds the journalistic world. The more news organisations become affected and guided by commercial interests and constraints, the more journalists view their duties as aiming to please their bosses (Berkowitz and Limor, 2003). Governmental positions are not immune to this either, and so the aforementioned is true not only in relation to the journalists, but to the risk managers and spokespeople as well. Preston and Metykova (2009) add to this discussion the evident and inherent tension between the editors' profes- 
sional demands, and the reporters' journalistic guiding principles. Luhmann (2000), too, has mentioned that the system of mass communication is bound to operate under an infinite cycle of obstructions and restraints caused by the intrinsic quality of the system.

\section{Discussion: how are audiences created and shared?}

Luhmannian society functions in a sound manner, but could just as straightforwardly put its own existence in danger. This contingent and differential portrait of societal functioning can only become trustworthy if an observer within the system observes them. Mass communication is perhaps the most complicated system of all in terms of its operations and observations. In this article, I have analysed risk communication as an operation meant to produce and share audiences. An understanding of risk communication as both an external irritation to society and part of the mass communication system allows us to view the way mass communication functions as a societal system.

The examination of risk-communicators' role perceptions has accomplished a few of the central aims of this paper:

- An extension of the scope of debate about the rather underdeveloped element of the audience in Luhmann's theory.

- A better understanding of how the system of mass communication works, in view of risk communication as an operation.

Audiences are end-targets of risk-communication processes, yet in terms of shared knowledge, the audience is the weakest link in the chain. Even though risk communication, as an operation, is all about the audience, it keeps defining, creating and sharing audiences by reproducing their relative ignorance. This is done by employing some core strategies, such as: the sorting of information (i.e., only certain fragments of information, rather than the full picture, are presented); using plain binary distinctions instead of giving away compound details; reducing complexities by rendering rationality; and using a business as usual approach.

Risk communicators are responsible for maintaining the operation of risk communication, hence they are the only ones able to observe themselves and, from this perspective, the system of mass communication. In this manner, they hold the foci of power, and, in a way, they seize the answer to society's own existence.

\section{Conclusion}

From Niklas Luhmann's perspective, systems in the society maintain constant communication with each other. Problems and difficulties that stem from risks are continually displaced from one system to another (Luhmann, 1989). Yet not only problems are shared. Risk communicators play a major role in defining, creating and producing audiences for the mass 
media system. Different audiences vary from one problem to another, and are created by the operation of risk communication and shared by all systems depending on context. This is how risk communication solves the difficulty of addressing different audiences with conflicting utterances. It transforms from system to system using the same operational tools (i.e., schema formation, binary coding, reduction of complexities and rationality). In this way, even though risk communication is primarily an operation of the mass communication system, it uses the reality of communication between the social systems to transform from one system to another. Risk communication is self-referential, but audiences are not. Both risk communication contexts and audiences are temporal, yet risk communication as an operation is not.

Risk communicators are defining audiences. They are the ones who decide who the audiences for each risk communication setting will be. In this manner, risk communication is nothing but an aid for society to keep the paradoxical cycle of observing and processing its self-created reality.

\section{References}

Aguado, J.M. (2009). Self-observation, self-reference and operational coupling in social systems: Steps towards a coherent epistemology of mass communication. Empedocles European journal for the philosophy of communication, 1, 59- 74.

Bauma, G.D. and Ling, R. (2004). The research process ( $5^{\text {th }}$ edition), Oxford University Press.

Beck, U. (2009). World at Risk, UK and USA: Polity press.

Beck, U. (1999). World Risk Society. Blackwell, Oxford.

Beck, U. (1995). Ecological Enlightenment: Essays on the Politics of the Risk Society. Humanities Press, Atlantic Highlands, NJ.

Beck, U. (1992). Risk Society: Towards a New Modernity. Sage, London.

Bergmans, A. (2008). Meaningful communication among experts and affected citizens on risk: Challenge or impossibility?. Journal of risk research, 11(1-2), 175-193.

Berkowitz, D. and Limor, Y. (2003). Professional confidence and situational ethics - assessing the socialprofessional dialectic in journalistic ethic decisions. Journalism and mass communication quarterly, 80(4), 783- 801.

Galtung J. and Ruge M.H. (1970). The Structure of Foreign News. In J.Tunstall, (ed.), Media sociology [pp. 258-298], London: Constable.

Giddens, A., (1990). The Consequences of Modernity, Polity, Cambridge.

Harrison, P.R. (1995). Niklas Luhmann and the theory of social systems. In D. Roberts (ed.), Reconstructing theory: Gadamer, Habermas, Luhmann [pp. 65-90], Melbourne University Press.

Heath, R.L. (2009). Crisis communication at the beginning of the $21^{\text {st }}$ century, keynote speech, Crisis communication at the beginning of the $21^{\text {st }}$ century conference, hosted by the International Research Group on Crisis Communication (IRGoCC), Ilmenau University of Technology (Ilmenau, Germany), October 8-10, 2009. 
Horsley, S.J. (2009). The influence of journalistic construction of disaster on crisis-adaptive audience information, paper presented in Crisis communication at the beginning of the $21^{\text {st }}$ century conference, hosted by the International Research Group on Crisis Communication (IRGoCC), Ilmenau University of Technology (IImenau, Germany), October 8-10, 2009.

Klinke, A. et al (2006). Precautionary risk regulation in European governance. Journal of risk research 9 (4), 373- 392.

Luhmann, N. (2000). The reality of the mass communication, (translated by Kathleen Cross), Stanford, Calif. : Stanford University Press.

Luhmann, N. (1998). Observations on modernity, (translated by William Whobrey), Stanford, Calif. : Stanford University Press.

Luhmann, N. (1993). Risk: A Sociological Theory. New York: Walter de Gruyter.

Luhmann, N. (1989). Ecological communication, (translated by John Bednarz), Chicago, Ill.: University of Chicago Press.

Preston, P. and Metykova, M. (2009). From news nets to house rules: organizational contexts. In P. Preston (ed.), Making the news: Journalism and news cultures in Europe [pp. 72-91], Routledge.

Preston, P. (2009). New news nets: media routines in a 'knowledge society'. In P. Preston (ed.), Making the news: Journalism and news cultures in Europe, Routledge, pp. 49-71.

Renn, O. (2006). Risk communication - Consumers between information and irritation. Journal of risk research 9(8), 833-849.

Renn, O. (2003). Acrylamide: Lessons for risk management and communication. Journal of health communication 8 (1), 435 - 441.

Renn, O. (1998). Three decades of risk research: Accomplishments and new challenges. Journal of risk research 1(1), 49- 71.

Sellnow, T.L., Seeger, M.W. and Ulmer, R.R. (2003). Chaos theory, informational needs, and natural disasters. Journal of applied communication research 30, 269-292.

Sellnow, T.L. (2009). Communication in the context of natural disasters: A chaos theoretical approach, paper presented in Crisis communication at the beginning of the $21^{\text {st }}$ century conference, hosted by the International Research Group on Crisis Communication (IRGoCC), Ilmenau University of Technology (Ilmenau, Germany), October 8-10, 2009.

Thompson, K.M. and Bloom, D.L. (2000). Communication of risk assessment information to risk managers. Journal of risk research 3(4), 333- 352.

Ulmer, R.R., Sellnow, T.L. and Seeger, M.W. (2007). Effective crisis communication: Moving from crisis to opportunity, Thousand Oaks, CA: Sage.

CDC - Center for Disease Control and Prevention (2002). Crisis and Emergency Risk Communication

\section{Notes}

1 This analytic approach considers how people construct their social/professional lives. It examines what actions are generally understood as "typical actions", which allows me in turn to understand "what it is like" to be $X$.

Daniela Korbas-Magal

PhD student

Department of Communication

Ben-Gurion University of the Negev, Israel

korbasma@bgu.ac.il 